Meta

Journal des traducteurs

Translators' Journal

\title{
Voice Linguists on the Record: An Introspective Investigation of Foreign-Language Transcribers at Work
}

\section{Denise Rudd et Janet Fraser}

Volume 45, numéro 2, juin 2000

URI : https://id.erudit.org/iderudit/004009ar

DOI : https://doi.org/10.7202/004009ar

Aller au sommaire du numéro

Éditeur(s)

Les Presses de l'Université de Montréal

ISSN

0026-0452 (imprimé)

1492-1421 (numérique)

Découvrir la revue

Citer cet article

Rudd, D. \& Fraser, J. (2000). Voice Linguists on the Record: An Introspective Investigation of Foreign-Language Transcribers at Work. Meta, 45(2), 193-209. https://doi.org/10.7202/004009ar
Résumé de l'article

Toute activité linguistique comprenant l'enregistrement et la transcription de la parole resterait normalement en dehors de la définition, même étendue, de l'interprétation et de la traduction, c'est-à-dire le transfert d'une langue à une autre d'un texte oral ou écrit.Il existe néanmoins un groupe apparemment disparate de langagiers dont le travail consiste à transcrire la parole avant de la transférer dans une deuxième langue. Ce groupe comprend les employés de services d'écoute (qu'on appellera ici " voice linguists "), les procès-verbalistes de l'ONU, les spécialistes des études de marché et les sous-titreurs.L'étude dont il est question dans cet article considère uniquement les "voice linguists "; elle a été réalisée d'après des témoignages et vise à étudier les processus utilisés ainsi que les compétences qui entrent en jeu dans ce travail. L'étude conclut que ces langagiers ont recours à la déduction ainsi qu'à un processus semblable au déchiffrage des rébus pour surmonter les difficultés de la compréhension orale, puis à une démarche entièrement différente, bien qu'essentiellement fondée sur la traduction, quant à l'expression écrite ultérieure. 


\title{
Voice Linguists on the Record: An Introspective Investigation of Foreign-Language Transcribers at Work
}

\author{
DENISE RUDD and JANET FRASER \\ University of Westminster, London, United Kingdom
}

\begin{abstract}
RÉSUMÉ
Toute activité linguistique comprenant l'enregistrement et la transcription de la parole resterait normalement en dehors de la définition, même étendue, de l'interprétation et de la traduction, c'est-à-dire le transfert d'une langue à une autre d'un texte oral ou écrit. Il existe néanmoins un groupe apparemment disparate de langagiers dont le travail consiste à transcrire la parole avant de la transférer dans une deuxième langue. Ce groupe comprend les employés de services d'écoute (qu'on appellera ici «voice linguists»), les procès-verbalistes de l'ONU, les spécialistes des études de marché et les sous-titreurs. L'étude dont il est question dans cet article considère uniquement les «voice linguists »; elle a été réalisée d'après des témoignages et vise à étudier les processus utilisés ainsi que les compétences qui entrent en jeu dans ce travail. L'étude conclut que ces langagiers ont recours à la déduction ainsi qu'à un processus semblable au déchiffrage des rébus pour surmonter les difficultés de la compréhension orale, puis à une démarche entièrement différente, bien qu'essentiellement fondée sur la traduction, quant à l'expression écrite ultérieure.
\end{abstract}

\section{ABSTRACT}

Even a broad definition of interpreting and translation - the interlingual transfer of the spoken and the written word respectively - would normally exclude any linguistic activity involving the recording and transcription of speech. However, an apparently unconnected group of language professionals, including foreign-language transcribers or 'voice linguists,' UN précis-writers, market research analysts, and film sub-titlers, is engaged in the transcription of speech coupled with its transfer into a second language. The study described in this paper centres on the work of voice linguists and uses introspective accounts to investigate the processes involved and to identify the skill-set they use. It concludes that the work of such voice linguists involves a unique combination of inferencing and puzzle solving to resolve the difficulties of aural comprehension and a distinct, but essentially translation-based, approach to the subsequent written expression.

\section{MOTS-CLÉS/KEYWORDS}

voice linguists, foreign-language transcribers, interlingual transfer, skill-set, introspective accounts

\section{Foreign-Language Transcription as a Non-Traditional Language Activity}

Gentile et al. (1996: 40), writing about the 'sight translation' interpreters are sometimes required to do, "one can argue that this activity straddles the two professional roles [of translation and interpreting], as do others such as sub- or sur-titling. Indeed, there are some areas of professional activity that cannot be classified easily as inter- 
preting or translation." Foreign-language transcription seems to be another obvious area, involving as it does a similar inter-mode combination of aural input and written output.

This work, performed by what we shall call 'voice linguists', involves monitoring foreign-language broadcasts, mainly for technical or media applications, and writing up either full transcripts or summaries/abstracts in a different language and for a specific user or purpose. Like sight translation, it is largely undocumented. Until a few years ago, in fact, virtually nothing had been written about it, aside from internal guidelines and historical studies of the BBC's Monitoring Service. However, with the collapse of the Soviet Union and the end of the Cold War, a certain amount of information has now emerged: the former Organiser of Soviet Monitoring at the BBC sheds some light on the history of foreign-language monitoring as practiced by that organisation at a crucial period in the history of Europe:

For 50 years now the BBC has been monitoring the world's public broadcasting services, listening to their news as they report it and turning it rapidly — at times immediately - into our news through the application of fast and accurate translation skills. [...] The work of monitoring is an unusual cross between interpreting and translating. We have to produce a full and accurate translation on paper, but our source material is what we hear rather than what we can see. (Hollow 1989: 72)

Here is an assertion, based on personal experience, that supports the assumption that foreign-language transcription (in its monitoring application) is a hybrid activity, combining key elements of interpreting and translating. Hollow further refers (1989: 74) to the need for monitors not only to "translate into good, idiomatic English" but also to "be very much at home in the contemporary culture of the country concerned $[\ldots]$ and able to think and act quickly when they spot the significant, the newsworthy point in the midst of the routine material." A traditional translator is not called upon to "spot the significant" but rather to render the source material in its entirety. Clearly, then, monitors are not acting solely as translators but bring an additional dimension to that particular activity.

There is also in Hollow's reference to aural, rather than visual, sources a hint of the unique difficulties of foreign-language comprehension encountered by the monitor/transcriber, who is working 'blind,' relying on his or her ears alone. This has been described more recently by Atkin (1997: 138), also writing about BBC Monitoring: "The foreign-language monitor's job sounds beguilingly simple - to listen, select and transcribe. And yet the first of these tasks - listening - can be fraught with problems." The listening skills identified by both Hollow and Atkin would not, however, normally be demanded of a translator, nor, under normal circumstances, would the selection skills to which Hollow refers be demanded of an interpreter. This article begins, therefore, with an assessment of the skill-sets involved in conventional translation and interpreting, neatly defined by Henderson (1987) as reading comprehension with written expression or aural comprehension with oral expression. With the boundaries of these skill-sets in place, the article then describes an experiment to identify the processes involved in foreign-language transcription as a basis for profiling the skill-set required for that activity, concluding with an attempt to analyse the extent to which voice linguists translate or interpret in a conventional sense and the extent to which they are, instead, engaged in a hybrid form of language transfer. 
This traditional pairing of skills along a reading/writing or listening/speaking divide tends to reinforce the notion that professional linguists function either in the world of the written word or in that of the spoken word. The working assumption made in this study is of a fairly broad definition of both translating and interpreting along this binary divide, yet even at this level of generality, it is difficult to pin down the skill-set required for either of these two fields of linguistic activity. If we exclude knowledge of both the source language (SL) and the target language (TL) and, for translation, such ancillary skills as word-processing or proof-reading, various lists of skills are either implicit or explicit in the profiles of the profession contained in the literature; sometimes these overlap, but more often, they are discrete. Nonetheless, we shall attempt here to draw out the areas of overlap.

\section{Traditional Skill-Sets}

In the case of translation, Hatim and Mason (1997) cite source- and target-text processing skills and "transfer skills" (not further defined), while Bell (1991:36) distinguishes between "reading (decoding) skills" and "writing (encoding) skills." Newmark (1988a: 17) expands on these and introduces a further dimension, identifying "two basic translation processes: comprehension, which may involve interpretation, and formulation, which may involve recreation" (emphasis added). The Canadian government's breakdown of translation into stages goes further still along this line, invoking specifically "l'assimilation, la conversion, la rédaction et le contrôle" (Secrétariat d'État du Canada 1988: 153); while the first two and the last of these occur in almost any list, whether practical or more theoretical, and are very general, the third sheds more light: "la rédaction suit de si près la conversion que ces deux opérations peuvent presque être tenues pour simultanées [...]. La traduction (rédaction) doit tenir compte de l'objet du document et du destinataire."

Samuelsson-Brown (1998: 5), meanwhile, identifies skill clusters, including "cultural understanding, information technology, decision-making, presentation, communication, linguistics and project management." Two writers, finally, cite personal characteristics rather than specific skills. Henderson (1987: 9) lists the stereotypes associated with translators as "introspective, surrounded by books, long-term memory, slow and painstaking, accurate, complete, thorough," while Robinson (1997: 14) describes the translator's "internal requirements" as "professional pride, income and enjoyment."

To sum up, then, translators need textual skills, the ability to reformulate a message (and, indeed, to perform as writers), cultural understanding combined with decision-making and presentation skills, and a willingness to take pains over detail and accuracy, as well as professional pride and pleasure in their work. It is interesting, however, that Newmark also includes the skill of 'interpretation' in his comprehension process. Indeed, Al-Shahab (1996: 35) makes this crossover explicit in his "five stages of translation" which are "editing the source text; interpreting the source text (intralingual); interpreting the source text in a new language (interlingual); formulating the translated text; [and] editing the formulation." If we exclude for the moment the initial and final editing stages, we are left with interpretation and writing. Implicit in the translator's work, then, at least according to these two scholars, is the skill of 'interpreting,' and while their use of the term clearly differs from, say, 
conference, liaison or court interpreting, both uses of the term imply an assessment process of some kind, involving the skill of evaluating a source text and selecting the best TL renderings according to certain criteria. While in translation these processes will probably be determined largely, if not wholly, by the end-user and purpose of the TL text, other factors come into play in interpreting proper.

Gentile et al. (1996: 40) comment that "the differences between the two activities [translation and interpreting] are often characterised in terms of the level of accuracy that can be expected from each [...]. Such views reflect a failure to recognise that the two activities require different skills and different aptitudes." It is, however, even more difficult to identify a list of skills involved in interpreting than in translating. This may be partly because interpreting has not traditionally been associated with academic investigation and theory in the way translation has (although this is beginning to change); thus, the literature is sparser and what there is tends to be more practical or technical. Nonetheless, such skills as attention division, a good shortterm memory, verbal fluency, and terminology research are implicit in the research summarised in Tommola (1995). Lambert (1991) cites anticipation and prediction, while Sunnari (1995) identifies the ability to condense the SL message to produce a coherent TL message through "macroprocessing," which she defines as "reconstructing the macrostructure from micropropositions [and] one of the central strategies of fluent simultaneous interpreting" (110).

Dillinger (1994) echoes both this and Al-Shahab's five stages of translation when he speculates that experienced interpreters "may have learned to be more selective in the surface information they process semantically, as a function of the text frame structure that is to be built with it ... comprehension in interpreting is characterised by all of the same component processes as listening ... with an emphasis on semantic processing, in particular proposition-generation, and text processing generally" (181, 185). This chimes with Henderson's (1987) set of stereotypes connected with interpreters: "outgoing, eloquent, empathy with people, short-term memory, quick, intuitive, approximate, summary, gist" (9, emphasis added). Against a skill-set for translation that includes textual and writing skills plus a painstaking approach, then, we have a skill profile for interpreting that includes a special type of listening coupled with the ability to anticipate and synthesise material on an ongoing basis, a 'gist' approach contrasted with the exhaustive approach of the translator.

The pairing of hearing plus writing, though, creates a further skill-set that crosses the traditional divide between these two worlds, and as we have already commented, it is this skill-set that is required in order to perform foreign-language transcription.

\section{The Study}

\section{Research methodology}

Methodological considerations were important in designing an experiment to assess the extent to which foreign-language transcription really is a hybrid activity. Merely to examine inputs (an acoustic signal in the SL) and outputs (a written translation or summary report in the TL), or to undertake quantitative measurements of how long it took to transcribe a given length of material or statistical analyses of observed 
behaviours (e.g. the number of times a particular dictionary was consulted over a given period), would merely have been to gather data (however useful) on what was being done; it would not have addressed how or why. To investigate these latter aspects, it was necessary to gain access to the actual process of hearing, understanding and composing, and to gain this access, it was necessary to turn to the field of psycholinguistics. Since the mind cannot be directly observed, psycholinguists have to devise experimental ways of determining how the mind works when processing language. Accordingly, a psycholinguistics-based experiment of some kind suggested itself as a means of gaining the necessary access.

Introspection has an established reputation in psychological research methodology and involves informants providing a verbalised account of how they perform a task-based activity (for a fuller account of the methodology, see Ericsson and Simon 1980). More recently, it has been employed by applied linguists in general and, more specifically, by translation researchers seeking to shift the focus of research away from 'product' and on to 'process' (see Meta 41-1 for a collection of articles on translation process research and Fraser (1996) for a full survey of translation research using this methodology).

The introspective method has limitations. First, it is generally agreed in the literature that it provides access only to strategies actively and consciously involved in execution of a task; highly practised or "automatised" processes are not brought into short-term memory while carrying out a task and cannot therefore be reported on. Second, Ericsson and Simon (1980) and Mann (1982) highlight constraints such as the psychological difficulties an instruction to verbalise may produce, for example interference from the difficulty of the task, from the informant's attempts to 'please' the researcher, or even from the informant's lack of vocabulary in which to verbalise. Third, there is some evidence that observed behaviour is always 'edited' in some way. Nevertheless, the method is, arguably, the only practicable means of gaining access to processes involved in a task (on which observation and product analysis rarely shed light) and, moreover, it has the merit of a proven track record in the broad subject area of this research.

The introspective method was therefore chosen to investigate the performance of a foreign-language transcription task. There are, however, several different forms of introspection, and a decision had to be made on how the information could best be elicited from the participants in the study, particularly in the light of the essential difference between this and previous studies, namely the spoken nature of the SL material.

The method most commonly used in translation research proper is the thinkaloud protocol, a concurrent verbalisation produced as the task is being performed. Introspection and verbalisation may also be retrospective and produced either immediately the task (or a part of it) is complete or some time later. The introspective account is most commonly recorded on audiotape although video recordings are becoming more common and, in the field of translation research, software is available that records all the changes made during the production of the final text, providing support for the comments made by the informant.

One important point at issue for the present study was whether the foreignlanguage transcribers would find their concentration and performance impaired to an unacceptable degree if asked to speak aloud while otherwise engaged in listening 
and writing. Daro and Fabbro (1994) showed that in simultaneous interpreting, the articulation itself of a spoken message in the target language affected the interpreter's ability to subsequently recall in any detail the content of the message. In the present experiment, there was, therefore, a concern (not tested experimentally) that where complex listening skills were involved, a requirement to verbalise could similarly inhibit recall of the processes involved.

A related concern involved the working environment itself which is already heavily equipment-dominated, including as it does a sophisticated audio transcription machine, headphones and foot pedals in addition to word-processors and other computer-based tools. Moreover, for a combination of reasons, it was very difficult for the researcher to be physically present when most of the participants were completing the experimental task, which would have required the experimental subjects to record their verbal protocol themselves. There was, therefore, a concern that to add a further requirement to operate a separate dictating machine might be an unwelcome distraction from the task at hand.

As a result, 'thinking aloud' was impractical, a practical constraint lent methodological weight by comments in the literature that the very act of trying to record how an activity is accomplished while actually doing it can intrude upon the activity and that data are more valid where there has been no pressure to verbalise. The subjects were, therefore, given a written set of instructions and asked to write down their comments as they completed their task. No time limit was imposed on subjects for completing the task. This method is what Mann (1982) has called "immediate retrospection" or what Cohen (1984) calls "self-observation," an inspection by subjects of their own behaviour in the allocated task. As will be demonstrated in the next section, not only was this the most practical form of introspection under these unusual circumstances, it was also successful in eliciting reports from the informants. As Fraser (1996: 68) has pointed out, "think-aloud methodology is more appropriate for eliciting the principles being used to resolve individual difficulties," whereas the aim in this study was to identify the nature of a previously undocumented activity.

\section{Subjects and task description}

The participants were five full-time, professional linguists working in a staff capacity as foreign-language transcribers in the UK. These five individuals had been employed in this work for 4 months, 3 years, 14 years, 20 years and 30 years respectively. Two were women and three men. All had English as their mother tongue and the main language into which they worked.

It may be useful here to reflect briefly on the work typically done by such staff. Almost invariably, foreign-language transcribers deal solely with audio input, such as a tape-recording of a foreign broadcast. In some cases, transcribers may be tasked with the purely monolingual job of literally transcribing what they hear in the original spoken language, producing what are accurately described as 'verbatim' transcripts to be either read directly by those with the ability to understand the information in the original or, sometimes, further processed in their written form by separate translators. However, such an approach is a rather inefficient means, costly in both time and human resources, of documenting what was said in the SL and relaying that to a TL readership. Transcribers are, therefore, frequently given the whole job of listening to 
the SL and producing a TL transcript at the same time. This is much more efficient, but unless the same level of detail is required as was contained in the original, an additional refinement is often introduced: the transcriber is given the further job of summarising the content of the original speech and, rather like the UN précis-writers, producing a TL abstract or a 'gist' as it is called in transcribers' terminology. Which of these three possible forms of transcript a foreign-language transcriber will be asked to produce will depend on the particular task at hand.

Faced with this range of possible 'products', it seemed appropriate to design an introspection-based experimental study around the production of a 'gist' in English, in order to investigate the entire potential process. The material to be transcribed in this way was a genuine recording, not edited by the researcher in any way as an artificial test-piece. It was the sound track of a 5-minute news item, in Russian, taken from a commercial source (Moscow News) and re-recorded onto a BASF C-90 audiocassette for replay on a Neal RW21 audiocassette transcription machine. The item was self-contained and featured a public meeting-cum-press conference held in 1989, organised by the Cinematographers' Union, and involving three different speakers. The principal speaker was the author and satirist Vladimir Voinovich, one of whose works was to be made into a film and who had briefly returned to the then Soviet Union from exile.

This particular item was chosen for three reasons. First, it represented a typical SL format and length. Second, it gave the participants in the test a somewhat different topic to work on from their normal, more technical range. This was designed to make the task less automatic than it might have been had they been assigned material on a more familiar topic, as a way of countering the 'automatisation' phenomenon referred to above. Third, the item dated from the period specifically referred to by Hollow (1989) and therefore represented a way of testing the assertions made in what little had been published on this particular form of linguistic activity. This also explains the time lag between the date of the broadcast (1989) and the date of the experiment (late 1996). To keep the scope of comments as broad as possible, no brief was given for this task, although one would usually be given under normal circumstances and, in fact, one was often assumed by the transcribers in the study, as we comment below in our analysis.

The instructions for the study read as follows:

"The exercise is aimed at providing a practical demonstration of the methodology and processes associated with transcription. To this end, I am asking the volunteers to do two things in parallel:

- firstly, to produce a gist in English of the enclosed 5-minute Moscow News recording dating from 1989 and,

- secondly (and more importantly from the perspective of the research aims), to create a detailed written log of how they actually carry out the task, as they do it.

The requirement is for a completely uncensored account of how a gist is constructed: i.e. what the transcribers are doing and thinking — and why. Nothing is too trivial or obvious for inclusion and, of course, there is absolutely no element of judging or testing involved here."

Four of the five transcribers completed the task in their usual working environment and one, with too heavy a workload to do this, carried out the task at home in his free time, using borrowed equipment and without some of the resources he nor- 
mally had available. Four of the five recorded their notes by hand and one on a wordprocessor. A post-task interview had been conducted with one of the five transcribers, who had acted as a pilot subject, and some of her comments from this interview are included in the report on the findings below. They are identified as such, while all other comments come from the transcribers' written notes.

\section{Findings from the Study}

All five transcribers adopted a structured approach to the task, which revealed the inter-related processes associated with both listening (understanding and reconstructing the incoming SL acoustic signal) and written expression (creating the TL gist). Although there were some variations in individual methodology, the transcribers essentially followed a four-stage procedure. This could be summarised under two underlying skill-sets: the aural comprehension skills of the interpreter, involving (1) listening all the way through the item, (2) noting down what was heard in as full or brief a version as the individual deemed necessary to ensure an accurate final product (in either the SL or the TL or a mixture of both) and (3) problem-solving with reference back to specific areas in the source speech; and the written expression skills of the translator, involving (4) producing a summary report in 'good' English. Most time was devoted to aural comprehension, aimed at recovering sufficient meaning and content of the source speech to be able subsequently to construct the written gist in the TL.

\section{Stage (1): aural comprehension - listening}

The first step, listening all the way through, is crucial to the entire undertaking. In terms of technique, it somewhat resembles that of consecutive interpreters, who are required to listen to all or a significant part of a SL speech and then reproduce it in spoken form once the speaker has finished. To this end, the interpreters listen attentively and make appropriate notes while the speaker is holding forth. Hatim and Mason (1990: 206), discussing textual relations in discourse, pause to consider this note-taking function:

The consecutive interpreter is closely acquainted with [...] major relational categories for, whereas in natural discourse the relations may not be explicitly signalled, they are always inferable and have to be made explicit in note-taking. This is so because the basic principle of note-taking [...] involves abbreviated or symbolic representation of propositions, arranged in a format which makes clear the relations between them. Training in this particular interpreting skill almost inevitably involves a form of discourse analysis and heightens awareness of inter-propositional coherence and the need to preserve it in translation.

The transcribers are also looking for connections throughout the entire discourse so that they, too, can compose a coherent end product. The approach they adopt, though, is subtly different, for they are listening in order "to get some idea of the content," "to establish the context" or "to get the general drift of the conversation" (as three of the participants separately described this stage of the process). This echoes Sunnari's (1995) and Dillinger's (1994) representations of the interplay between listening and comprehension in interpreting. However, notwithstanding the fact that 
this is an aural rather than a reading comprehension process, it also somewhat resembles the approach advocated by Newmark for translators (1988b: 11):

You begin the job by reading the original for two purposes: first, to understand what it is about; second, to analyse it from a "translator's" point of view [...] You have to determine its intention and the way it is written for the purpose of selecting a suitable translation method and identifying particular and recurrent problems.

This blend of translation and interpreting skills provides early evidence that foreign-language transcription is a separate, hybrid activity. A major factor is that unlike interpreters, transcribers can listen more than once to the spoken discourse, i.e. they can afford to let it play through initially (in part or in whole) without making notes because they can go back to the beginning of the speech and make as many detailed notes as they need (stages 2 and 3 ), focussing on areas posing a difficulty for aural comprehension and working towards gathering the information needed to produce the written gist (stage 4).

While transcribers are not unique in having this 'benefit of hindsight,' they are in the special position of having the benefit of being able to listen back through spoken discourse. This freedom in relation to the source speech emerges as one of the distinct features of the activity, although, of course, one that is comparable with the conventional translator's unlimited access to the source text (although in the case of both groups, the pressure of deadlines may make repeated access impracticable or severely limit it).

\section{Stages (2) and (3): aural comprehension - note-taking and problem-solving}

The findings under this sub-skill area can, perhaps, best be further divided into four, overlapping, areas: hypothesis-forming; inferencing; lexis, syntax and discourse features; and acoustic clues.

i) Hypothesis-forming. Having completed the preliminary listen-through, one of the transcribers explained in brief terms how he tackled the recovery of the meaning of the source speech:

Step 2: Back to the beginning and try to get down the basic content by dividing it up into small sections. No attempt is made at this point to work out the meaning of every word. What is sought is a rough idea of the meaning of the whole in general. [...] Step 3: Try to sort out the bits that were not fully understood in the previous run-through.

Another participant accounted for this activity as follows:

I start playing the tape again, this time to listen for the details. [...] I like to break a long item down into sections. I make the breaks where there is a subject-change. Makes it easier to approach a long item. I'll tend to work in those sections, especially if I'm convinced the subject isn't addressed anywhere else in the item. In that case, I may do all three passes [stages 1-3 in our numbered list] on that section at one time if I want to finish it right away.

Here, both transcribers are revealed as performing a kind of structural analysis of the spoken text, looking for what appear to them to be self-contained 'chunks' of material to work on. This second study participant continued her explanation of her approach at some length, which is worth reproducing in the original detail because 
of the thorough insight it provides into the aural comprehension process she undertakes:

If it's an important section and there are some key words missing, I'm likely to give it some time before I come back to it. Sometimes you have to approach something with fresh ears before it makes sense to you. Another technique is what I call 'sneaking up on it from behind'. Sometimes you fail to hear a word because you're breaking up the sounds incorrectly. If you've gone past the word or phrase, you can rewind the tape a bit at a time to get back to the problem area. This necessarily forces you to break up and hear the sounds differently. May sound silly, but it has worked on many occasions for me. Sometimes it's the only way to get rid of your initial notion, which you know is incorrect.

Strategies of this sort are explained in Fromkin and Rodman (1993: 456):

The psychological stages and processes that a listener goes through in comprehending the meaning of an utterance are very complex. [...] Some psycholinguists suggest that speech perception and comprehension involve both top-down and bottom-up processing. Top-down processes proceed from semantic and syntactic information to the sensory input. Using such 'higher-level' information, it is suggested that we can predict what is to follow in the signal. Bottom-up processes move step-by-step from the incoming acoustic signal to semantic interpretation, building each part of the structure on the basis of the sensory data alone.

The evidence from the verbal accounts seems to indicate that in forming hypotheses about the meaning of the SL material, the transcribers set out with a predictive, topdown approach, moving from the general to the particular. Only when the top-down approach failed, though, did they home in on specific data and feature analysis. As one commented:

If I lost track of what was being said due to missing a couple of words, I let the tape play at least to the end of the sentence or maybe into the next sentence to try to regain the thread before going back to work on the individual lost word or words. That was important for helping to determine what type of word I was missing and how it might fit in the sentence. Sometimes (or even often) I make a guess on that score and it turns out to be wrong, but I need to work with some hypothesis.

ii) Inferencing. Critical to this activity is a process of inference, described in strikingly similar terms, though in a different context, by Brown and Yule (1983: 33-34):

Since the discourse analyst, like the hearer, has no direct access to a speaker's intended meaning in producing an utterance, he often has to rely on a process of inference to arrive at an interpretation for utterances or for the connections between utterances. $[\ldots]$ We are more likely to operate with a rather loose form of inferencing (which may turn out to be wrong) but, as discourse processors, we seem to prefer to make inferences which have some likelihood of being justified and, if some subsequent information does not fit in with this inference, we abandon it and form another.

The predictive and inferencing abilities associated with top-down processing appear to be what help the transcribers reconstruct the incoming acoustic signal and mentally fill in any gaps when the audio quality or the speech becomes unclear. The pilot subject said she regarded the work as being "like a puzzle" where "you start listening and think, 'What's this all about?' and, even, 'Am I going to be able to work out what's going on?' but, at the end, you do. It's satisfying." Newmark (1988b: 8) picks up this 
theme in his profile of the passionate translator: "The personal pleasure derived from translation is the excitement of trying to solve a thousand small problems in the context of a large one. Mystery, jigsaw, game, kaleidoscope, maze, puzzle, seesaw, juggling... the chase after words and facts is unremitting and involves imagination."

Here, then, we see evidence that resembles aspects of a performance of both a translator and an interpreter. Henderson (1987: 127) comments that "It is inherent in the interpreter's function that he [sic] be prepared to let a problem go if no immediate solution presents itself and pass on to the next one. The translator, on the other hand, spends much time isolating and worrying out solutions to a few major problems."

Unlike translators, though, simultaneous interpreters are under a particular pressure to keep pace with the speaker, no matter how rapidly he or she speaks. Their material is, therefore, externally rather than internally paced and they have little, if any, control over the pacing of the incoming material. Interpreters deal with this problem by depending heavily on short-term memory, combined with a particularly highly-developed ability to predict the likely end of a phrase or sentence, the socalled 'cloze' facility. 'Cloze' is a language testing technique in which gaps replace words at regular intervals in a text, enabling teachers to assess learners' comprehension by the extent to which they are able to fill the gaps with the correct, or at least a plausible, word. As Lambert (1991: 588) explains, "the term comes from the psychological concept of closure, the perception of apparent wholeness of visual or auditory inputs that are actually incomplete"; moreover, this ability to anticipate and predict, says Lambert, is "constantly called into play during simultaneous interpretation," and thus represents one of the particular skills an interpreter must have or needs to develop.

Indeed, McDonough (1995: 106) argues that "[studies show that] ability in 'cloze' tests is heavily contaminated by an intellectual or cognitive variable, field independence, and does not directly reflect linguistic proficiency" (emphasis added). Ellis (1986: 114-116) explains field dependence and independence as poles on the language-learning ability continuum; those with a high degree of field independence, he argues, are among other things more likely to rely on their internal frame of reference than on an external one when processing information, to have the analytical ability to break a field down into its component parts, and to have a clear sense of their own identity. Here, we see echoes of the 'macroprocessing' strategies in interpreting, referred to above (Sunnari 1995), involving personal judgement, analytical ability, and confidence in the professional role: the research described found that expert interpreters synthesised while trainees

[had] to use a great deal of their capacity on comprehending and trying to follow the speaker [and so] failed to form a general idea of what the speaker [was] aiming at. [...] While the synthetic strategy is likely to imply a greater processing effort during the comprehension stage, the effort needed [for] target message production and articulation is reduced, leaving more capacity for, e.g., the monitoring phase. [...] Experienced interpreters know how and when to apply macroprocessing.

In this respect, transcribers appear to function more like simultaneous interpreters, using an intuitive approach combined with analytical ability to select material and identify the gist rather than exhaustive reproduction. The transcriber quoted at 
length above could, moreover, be described as using her own variant of the simultaneous interpreter's 'cloze' faculty when she constructed her 'hypothesis' as to what a missing word or passage might be. She was not, however, under the same immediate pressure; transcribers' material is internally paced, and their ability to alter the speed of the speech if they wish, or simply to stop the tape while they jot down a note, means that they do not have to develop the skills an interpreter needs in order to keep pace with a fast speaker. To that extent, transcribers function more like translators with unconstrained access to the source text, although the ability to alter the speed of a tape or stop and restart it at will is a technical function unique to this task's aural comprehension process. Other tools of the trade also add their own dimension: as we have already commented, transcribers are equipped with the headphones familiar to the conference interpreter, a fairly sophisticated audio transcription machine, and the pen and paper or word-processor familiar to the translator. They also, however, have available rather more sophisticated on-line tools than are included in standard word-processing packages, as we explain below.

iii) Lexis, syntax and discourse features. These, too, formed a crucial part of the aural comprehension skills. One particular difficulty transcribers face (and one never confronted by translators nor, usually, interpreters) is that of looking up a word they have never heard before but are unable to see. One subject commented on the computer-based features of a modern office environment that can assist the transcriber:

I use an on-line reference aid that contains 14 different dictionaries, which I can search at once. It is enough to hear and recognize the root of a word in order to look it up here. Wildcard characters give much flexibility. Of course, if it's an unfamiliar word, you go for the root first.

Another referred to a glossary, sorted into reverse alphabetical order from the end of the word, which enabled him to build up a word from its ending; no other linguist would need to look up words from the middle, the root or the end. This evidence of a crossword-puzzler's approach to the puzzle-solving aspects of foreignlanguage transcription echoes the conventional translator profile, yet is manifest in an interpreter-like environment, giving further support for a hybrid skill-set. Henderson's (1987: 127) question is left hanging tantalisingly in the air, however: "Whether the possession of this particular and limited kind of problem-solving capacity in the translator - or its relative absence in the interpreter - is inherent or inculcated $[\ldots]$ is another question."

The need to understand and make sense of what they hear leads transcribers to employ all the means at their disposal to this end. It goes without saying that an indepth knowledge of the grammar and syntax of the SL is a sine qua non for any professional engaged in an interlingual activity, but the peculiarities of hearing, understanding and reconstructing recorded speech bring their own challenges in this respect. Collocations provide important clues as to the missing components, and even inflection can be a help: "hearing an unfamiliar word in its declined form is invaluable in recovering it," commented one transcriber.

Repetition by the speaker, a cohesive feature of spoken discourse, was also of assistance, with one transcriber commenting:

I got stuck with the name of the book [...] it just came to me after several repeats. However, it is a transcription technique to look for words and hints throughout the remainder 
of the text for words you can't get at once. It can save a lot of time fruitlessly paging through dictionaries.

This accords with Fraser's (1994) portrait of experienced professional translators who showed a high level of tolerance for uncertainty or ambiguity and a willingness to let the meaning of an unfamiliar term 'emerge' both from context and from information available at later stages in the text. However, a feature of interpreting not shared with conventional translators - exploiting acoustic clues in the source speech - was a further important element in the skill-set when it came to aural comprehension.

iv) Acoustic clues. One transcriber commented, "I could tell this was not a straight news broadcast right away by the quality of the sound. The volume of the voice was not steady. This frequently happens when someone is talking into a microphone at a podium, etc. Of course, the applause later was another good clue."

The pilot subject also noted the "strange background noise," which she identified as applause and used to draw the conclusion "[There's] obviously an audience there, so definitely a press conference." She picked up, too, on the tone of voice when observing that Voinovich "doesn't sound bitter" and on the register of another speaker's opening remarks, which she thought sounded as though he was reading from a prepared text. (He was, indeed, making a stereotyped 'welcome speech,' which she evidently identified on the basis of its formal tenor and likened to similar speeches by applying her awareness of intertextuality.)

All the transcribers looked for and identified the fact that there were three different speakers, based on voice quality, style of delivery and content of what was being said. One of them inferred and noted that Voinovich was actually answering a series of questions, even though the broadcasters had edited the questions out of the original Moscow News report.

While the ability to make the necessary inferences from acoustic clues is not unique in language work, the requirement almost certainly is, for in the vast majority of cases, neither interpreting nor translating calls for quite the powers of imagination and deduction that are manifestly so central to the foreign-language transcription process. Furthermore, these are inextricably linked to the complete absence of any visual evidence to assist understanding in most of the work typically done by foreign-language monitors; even where TV broadcasts are being monitored, monitors still work overwhelmingly from audio rather than audio-visual sources (and not always high-quality ones either). Not only is it difficult to look up an unknown word without seeing it on the printed page, it is also difficult to reconstruct the circumstances of a debate or interview at one remove. By and large, interpreters are present (even if in a booth) at the event at which they are performing the interpretation yet, as two of the transcribers commented, "A transcriber can't see the speaker(s), thus making it more difficult to establish a context as he/she is deprived of visual cues" and "You can't see any of the body language." Monitors are therefore working almost wholly in the dark as far as paralinguistic cues are concerned, making their deductive and imaginative skills all the more necessary.

It is evident from the observations made by the foreign-language transcribers that they therefore made extensive use of the techniques associated with the analysis of spoken discourse in performing their task. The discourse analytical function 
comes across so strongly, in fact, that it is tempting to substitute 'foreign-language transcriber' for 'discourse analyst' in some of the literature on the latter's rôle and gauge how well the substitution works. For present purposes, a selective comparison of what was observed in the course of the introspective study with Brown and Yule's (1983) description of how an actual analyst of spoken discourse sets about his or her work will serve to illustrate the notional parallels:

In general the discourse analyst works with a tape-recording of an event, from which he then makes a written transcription, annotated according to his interests on a particular occasion [...] We have no standard conventions for representing the paralinguistic features of the utterance which are summarized as 'voice quality', yet the effect of an utterance being said kindly and sympathetically is very different from the effect if it is said brutally and harshly. [9-10] It seems reasonable to suggest [...] that these variables, together with pause and intonation, perform the functions in speech that punctuation, capitalisation, italicisation, paragraphing etc. perform in written language. [...] The response of most analysts [...] is to present their transcriptions of the spoken text using the conventions of the written language. [10-11]

\section{Stage (4): written expression}

Having satisfied themselves that they had correctly understood the source speech, the transcribers then used the notes they had made as a source for the final step, the production of a written, TL text for a (real or putative) end-user. To this end, they needed to go beyond the production of a transcript that merely presents the spoken text in a written form. One of the transcribers, commenting partly on generalised rather than specific procedures, reported:

My next step is to take off the headphones, look at what I have written in English and make a decent summary out of it. It was quite easy to do after all the other work. You have to touch on who, what, when, where, why and how to the extent that they are covered in the item you are working with. A summary sentence or paragraph is necessary to ease the reader into it. Details follow. I judge the level of detail by who I am writing the summary for. What do they need? It's entirely possible that one person would need only the summary sentence/paragraph. I couldn't judge that here, so in the details I contented myself with telling the story in an abbreviated form, taking out repetitions and the story-telling form of the original.

Here, the transcriber is commenting on the need to tailor the gist to the intended recipient and echoes the point made by Hatim and Mason à propos of the 'literal' versus 'free' debate in translation when they write that "the beginnings of a solution to the problem will depend, to borrow a well-known sociolinguistic formula, on who is translating what, for whom, when, where, why and in what circumstances" (1990: 6). As abstractors, the transcribers are operating at the 'free' end of the spectrum but will nonetheless work to a brief, either specifically allocated or as in this study - assumed on the basis of experience of what clients typically need:

I originally gave a gist of each speaker's speech in turn. Once I had firmly established context, however, it seemed acceptable not to individualise the journalist/broadcast team, and provide only a short introductory sentence. [...] For a news report, the third person seemed most appropriate. [...] As the speaker [Voinovich] is quite verbose, the temptation was to strip his speech to a bare minimum. However, as he is a writer and 
spoke with some passion, I felt it appropriate to retain some detail and idiom to put this across.

The evidence suggests that, once they are functioning as writers, the transcribers effectively assume a rôle that is almost identical to that of translators proper and that clearly focuses on the end-user and the purpose of the task. However, translators operate in a diverse client- or agency-driven market without common standards, whereas voice linguists working in a staff capacity are more likely to be schooled in a corporate approach. Atkin (1997: 138), writing about BBC Monitoring (based at Caversham), sheds interesting light on this (and, incidentally, uses the term 'translation' to describe the work):

Monitors use a variety of approaches, depending on the nature of the text and its audience, but [the] tension between the literal and idiomatic approach is always there in the translation. At Caversham, though, the Cold War exerted a particularly deep influence, impelling translators to take the more literal approach. During the Cold War, language in the Communist bloc was used in a very precise way by the Party to maintain strict ideological control and consistency. The language was often coded, sending messages signalling change, and formulaic. The codes and formulas had to be rendered faithfully and consistently, so that analysts and Kremlinologists could look for clues to shifts in emphasis, thinking or policy [...] This led to translations with a lot of transference and literalisms, but given the needs of the target audience it was in many cases an appropriate approach.

The participant in the study who wrote this about her approach to the written expression procedure commented on this constraint on the transcriber's freedom to relay the content at the expense of the form:

Once I have reached this stage I would normally not listen to the item again. However, when dealing with complex subject matter and in poor audio quality, I may take one more run through with the Russian tape and my English summary, just to make sure the two match up. Sometimes you can get a little too far from the Russian.

In revising her work in this way, the foreign-language transcriber is performing a classic translation step that, as Newmark (1996: 122) observes, "goes by the board" in interpreting. In this particular Paragraph on Translation, he is commenting on the features that are normally taken to distinguish translating from interpreting and briefly explores the reading comprehension/oral expression skill combination used in 'sight translation'. Where, however, the interpreter does have the opportunity to perform revision of a speech to be published at a later date, Newmark draws the interesting conclusion (from the point of view of the present research) that "the gap between translating and interpreting is narrowed," although he insists that the gap remains. What the findings of this experimental study appear to demonstrate, though, is that, when aural comprehension and written expression are brought into

play, as in the case of foreign-language transcription, it is, in fact, less a matter of the gap being narrowed and more a matter of the gap being filled by a hybrid practice.

\section{Conclusions}

The introspective study yielded a wealth of information on the processes involved in 'foreign-language transcription,' particularly the structured approach adopted for 
understanding and reconstructing the SL speech, its conversion into the TL, generally via a step of noting parts of it down (in either the SL or the TL, or a mixture of both, according to personal preference), and the production of the TL gist.

In an interpreter-like profile, the aural comprehension process was revealed as relying on careful listening coupled with textual and discourse analysis to establish the type and register of the discourse, using different linguistic cues (including prosodic features) to identify different speakers and their rôle in the discourse and blending a thorough knowledge of the grammar, syntax and vocabulary of the SL with all available information associated with the recording (including information extraneous to the text) in order to build up a picture of the overall context. Evidence of a judicious combination of both top-down and bottom-up processing to solve individual problems was also observed. The written expression process, by contrast, manifested a clear awareness of audience needs and evidence of the subjects' working to a precise brief, based on corporate practice, which seems (on the basis of similar introspective studies) to be a feature of the working methods of professional translators.

Thus, although the transcribers' approach to this process was initially similar to that typical of interpreters, the change in status of the source speech (from ephemeral in the case of interpreting to permanently recorded and manipulable in the case of foreign-language transcription) inspired a distinctive approach. Essentially, this was a far more thorough and painstaking example of speech recovery, based on a highly-developed problem-solving ability, than is normally found in interpreting; significant factors in the cultivation of this ability included strategies for dealing with unfamiliar lexis or with the absence of any visual cues. For written expression, then, the transcribers switched to functioning as more conventional translators and made a point of revising the TL text and making choices as to style and content against the perceived needs of their audience, although the change in mode from the spoken to the written word gave rise to challenges and freedoms of expression not normally encountered by, or always available to, the traditional translator.

It seems, then, that foreign-language transcription is a hybrid of both interpreting and translating but with some distinct characteristics. With such a small sample, the findings are, of course, tentative, especially given the limitations of a constructed experimental task. Nevertheless, as a first step towards systematising what voice linguists do, the research goes some way to meeting the challenge identified by Gentile et al. (1996) and may also help to identify factors to be heeded in the selection and training of such professionals. As well as the requisite hybrid skill-set identified here, it may be that successful voice linguists need also to manifest a hybrid personality, or at least a hybrid professional profile. Many elements of such a profile have both emerged from this study and been identified in Henderson's (1987) personality assessment of translators and interpreters: translators, he found, were more intelligent, apprehensive, self-sufficient and reserved and somewhat more affected by feelings than interpreters, while interpreters were more imaginative and tense and somewhat more venturesome than translators. On the basis of this study, voice linguists need imagination and a willingness to take risks in making and continually revising their working assumptions about what they hear, but have to link this with high levels of self-motivation and self-sufficiency in applying rigorous standards of accuracy and quality to their written output. 


\section{REFERENCES}

AL-Sнанав, O. S. (1996): Interpretation and the Language of Translation, London, Janus Publishing Company.

Atkin, M. (1997): “The Craft of the Monitor," The Linguist, 36-5, pp. 137-139.

BeLL, R. T. (1991): Translation and Translating, London, Longman.

Brown, G. and G. Yule (1983): Discourse Analysis, Cambridge, Cambridge University Press.

Cohen, A. (1984): "Studying Second Language Learning Strategies: How Do We Get the Information?," Applied Linguistics, 5-2, pp. 101-112.

DARo, V. and F. FABbro (1994): "Verbal Memory During Simultaneous Interpretation: Effects of Phonological Interference," Applied Linguistics 15-4, pp. 365-381.

Dillinger, M. (1994): "Comprehension During Interpreting: What Do Interpreters Know That Bilinguals Don't?," Bridging the Gap: Empirical Research in Simultaneous Interpreting (S. Lambert and B. Moser-Mercer, eds.), Amsterdam, John Benjamins Translation Library, pp. 155-189.

Ellis, R. (1986): Understanding Second Language Acquisition, Oxford, Oxford University Press.

Ericsson, K. A. and H. Simon (1980): "Verbal Reports as Data," Psychological Review 87-3, pp. 215-251.

Fraser, J. E. (1994): “Translating Practice into Theory: A Practical Study of Quality in Translator Training," ITI Conference 7 Proceedings (C. Picken, ed.), London, ITI, pp. 130-142.

- (1996): “The Translator Investigated," The Translator, 2-1, pp. 65-79.

Fromkin, V. and R. Rodman (1993): An Introduction to Language, Fort Worth, Harcourt Brace.

Gentile, A., U. Ozolins and M. Vasilikakos (1996): Liaison Interpreting, a Handbook, Melbourne, Melbourne University Press.

Hatim, B. and I. Mason (1990): Discourse and the Translator, London, Longman.

- (1997): The Translator as Communicator, London, Routledge.

Henderson, J. (1987): Personality and the Linguist, Bradford, Bradford University Press.

Hollow, M. (1989): “The Glasnost Explosion: Monitoring Soviet Broadcasts in a Time of Change," ITI Conference 3 Proceedings (C. Picken, ed.), London, ITI, pp. 72-75.

LAmbert, S. (1991): "Aptitude Testing for Simultaneous Interpretation at the University of Ottawa," Meta, 36-4, pp. 586-594.

McDonough, S. H. (1995): Strategy and Skill in Learning a Foreign Language, London, Edward Arnold.

Mann, S. (1982): "Verbal Reports as Data: A Focus on Retrospection," Methods and Problems in Doing Applied Linguistic Research (S. Dingwall and S. Mann, eds), Lancaster, University of Lancaster.

Newmark, P. (1988a): Approaches to Translation, London, Prentice Hall.

- (1988b): A Textbook of Translation, London, Prentice Hall.

- (1996): "Interpretation Theory" (Paragraphs on Translation 44), The Linguist, 35-4, p. 122.

Robinson, D. (1997): Becoming a Translator, London, Routledge.

Samuelsson-Brown, G. (1998): A Practical Guide for Translators, 3rd ed., Clevedon, Multilingual Matters.

Secrétariat d'État du Canada/Department of Secretary of State of Canada (1988): Aide-mémoire d'autoperfectionnement à l'intention des traducteurs et des rédacteurs, Ottawa, Department of Secretary of State of Canada.

Sunnari, M. (1995): "Processing Strategies in Simultaneous Interpreting: 'Saying It All' vs. Synthesis," Topics in Interpreting Research (J. TommolA, ed.), Turku, University of Turku Press, pp. 109-119.

Tommola, J., ed. (1995): Topics in Interpreting Research, Turku, University of Turku Press. 